\title{
Análise do perfil de visitantes de parques zoológicos de Santa Catarina: o pensar do público de 2000 a $2019^{1}$
}

\author{
Analysis of the visitors profile of zoo parks in Santa Catarina: the public thinking \\ of 2000 to 2019
}

\section{Análisis del perfil de visitantes de parques zoológicos de Santa Catarina: el pensar del público de 2000 hasta 2019}

\author{
Maria Amélia Pellizzetti ${ }^{2}$ \\ Tito César Marques de Almeida ${ }^{3}$ \\ Joaquim Olinto Branco ${ }^{4}$
}

\begin{abstract}
Resumo
Este trabalho buscou identificar a percepção dos visitantes de quatro parques zoológicos de Santa Catarina, no período compreendido entre 2000 e 2019, através da aplicação de 2.178 entrevistas semiestruturadas (questionários), da análise de 12.909 notícias através do uso da ferramenta google alerts e de observação não participante. Considerando-se as razões da existência e os aspectos de zoológicos ideais, o motivo das visitas e os meios de informação adequados, observa-se um padrão relacionado à idade dos visitantes e as expectativas que cada grupo possui. É importante aprofundar as discussões e as críticas sobre zoológicos como espaços educadores sustentáveis para apropriação e disseminação de conceitos científicos, com o desenvolvimento de práticas cotidianas incorporadas à rotina dos parques. Dessa maneira, os zoológicos possuem grandes desafios para que ocorra a ampliação dessa percepção e dos esforços para que a conservação ex situ seja entendida e apoiada pela sociedade civil.
\end{abstract}

Palavras-chave: Percepção. Percepção Ambiental. Educação Ambiental. Zoológicos.

\begin{abstract}
This work aimed at identifying the perception of visitors of four zoo parks in Santa Catarina, in the period of 2000 and 2019, through application of 2.178 semi-structured interviews (questionnaires), 12.909 news analysis using tools such as google alerts and the no-participant observation. Considering reasons of existence and aspects of the ideal zoologic, visits purpose and means of suitable information can be observed a standard related to the visitors age and the expectations that each group has. It is important to pursue discussions and critics concerning the use
\end{abstract}

\footnotetext{
${ }^{1}$ Este artigo é fruto da tese de doutorado intitulada Zoológicos de Santa Catarina: aspectos de gestão e percepção dos visitantes sobre a temática ambiental, aprovado no Comitê de Ética em Pesquisa da Universidade do Vale do Itajaí (CEP UNIVALI), com o parecer consubstanciado № 1.624.741, desenvolvida pela primeira autora, sob orientação do segundo e terceiro autor, junto ao Programa de Pós-graduação em Ciência e Tecnologia Ambiental (PPCTA) da Universidade do Vale do Itajaí.

${ }^{2}$ Doutora em Ciência e Tecnologia Ambiental (PPCTA) pela Universidade do Vale do Itajaí (UNIVALI). Mestre em Engenharia Ambiental pela Universidade Regional de Blumenau (FURB) e especialista em Gestão e Manejo Ambiental em Sistemas Florestais pela Universidade Federal de Lavras (UFLA). Graduada em Ciências Biológicas - ênfase em biotecnologia pela UNIVALI. Professora efetiva do Instituto Federal de Educação, Ciência e Tecnologia Catarinense Campus Camboriú (IFC Camboriú). Santa Catarina. E-mail: pellizzetti@hotmail.com

${ }^{3}$ Doutor em Ecologia e Recursos Naturais pela Universidade Federal de São Carlos; Mestre em Biologia (Biociências Nucleares) pela Universidade do Estado do Rio de Janeiro. Professor Titular da Universidade do Vale do Itajaí (UNIVALI). Santa Catarina. E-mail: tito@univali.br

${ }^{4}$ Pós-Doutor em Ecologia e Recursos Naturais pela Universidade Federal de São Carlos. Doutor em Zoologia pela Universidade Federal do Paraná; Doutor em Ecologia e Recursos Naturais pela Universidade Federal de São Carlos. Mestre em Zoologia pela Universidade Federal de São Carlos. Professor Titular da Universidade do Vale do Itajaí (UNIVALI). Santa Catarina. E-mail: branco@univali.br
} 
of zoos as sustainable educated spaces to the appropriation and the dissemination of scientific concepts, with the development of everyday practices incorporated to the parks' routine. Therefore, zoos have great challenges to occur the increase of this perception and the effort in order to the ex situ conservation should be understood and supported by the civil society.

Key words: Perception. Environmental perception. Environmental education. Zoologic.

\section{Resumen}

Esta investigación ha intentado identificar la percepción de los visitantes de cuatro parques zoológicos de Santa Catarina, en el período comprendido entre 2000 y 2019, a través de la aplicación de 2.178 entrevistas semiestructuradas (cuestionarios), del análisis de 12.909 noticias a través del uso de la herramienta google alerts y de la observación no participante. Cuando las razones de la existencia y los aspectos de zoológicos ideales son consideradas, el motivo de las visitas y los medios de informaciones adecuados, se observa un padrón relacionado a la edad de los visitantes y a las expectativas que cada grupo posee. Es importante profundizar las discusiones y las críticas sobre zoológicos como espacios educadores sustentables para apropiación y difusión de conceptos científicos, con el desarrollo de prácticas cotidianas incorporadas a la rutina de los parques. De esta manera, los parques zoológicos poseen grandes desafíos para que ocurra la ampliación de esa percepción y de los esfuerzos para que la conservación ex situ sea entendida y apoyada por la sociedad civil.

Palabras-clave: Percepción. Percepción Ambiental. Educación Ambiental. Parques Zoológicos.

\section{Introdução}

A relação humano-animal e a manutenção de animais sob cuidados humanos datam de milênios, mas apenas recentemente, nas últimas três décadas, a preocupação com o bem-estar foi reconhecida como ciência (SAAD; SAAD; FRANÇA, 2011), ampliando a percepção ambiental sobre a fauna.

O desenvolvimento histórico dos zoológicos tem sido um espelho das mudanças sobre o relacionamento entre humanos e animais (MILITÃO, 2008), que vêm retratando, com fidedignidade, as mudanças de opinião de seus frequentadores ao longo do tempo. Segundo Lopes, Bosa e Silva (2011), nesses locais as informações sobre fauna não são tratadas apenas como biológicas, mas promovem o envolvimento dos visitantes com os animais e com questões ambientais. Assim, os parques zoológicos ampliam, consideravelmente, as percepções e os conhecimentos dos seus visitantes sobre a biodiversidade, a Educação Ambiental (EA) e a reintrodução de espécies nativas (CHRISTOFFERSEN; BRANCO; FURTADO, 2013; MENDES, 2014; ARAGÃO, KAZAMA, 2014).

O termo percepção deriva do latim perceptio, correspondente à compreensão/percepção ou percipere, que significa apreender através dos sentidos (audição, tato, olfato, paladar e a visão), promovendo a interação do homem com o mundo, resultando no planejamento eficaz do ambiente (FERREIRA, 2005). A percepção ambiental em locais informais de ensino como os zoológicos pode ser uma oportunidade concreta para avaliar os possíveis obstáculos na transmissão de informações ao público, que irão fomentar um senso crítico e ético ambientalmente correto (ARAGÃO; KAZAMA, 2014).

A construção dessa percepção está intimamente relacionada à vivência do indivíduo com seu entorno (SILVA et al., 2006) e envolve cinco elementos básicos: motivação, percepção como processo psicológico de interiorização do mundo através da interpretação dos sentidos, cognição, avaliação ou julgamento e conduta como elemento finalizador do processo (DEL RIO, 1991, 1996), gerando comportamentos distintos em relação ao meio ambiente (FERREIRA, 2005). Aproveitando sentimentos de empatia e curiosidade dos visitantes, os parques zoológicos podem desempenhar papel importante na educação não formal de seu público (FURTADO; BRANCO, 2003). 
Na programação atual dessas instituições a EA é uma ferramenta eficiente para alterar o paradigma antigo de ver animais como seres enjaulados (ACHUTTI, 2003). Entretanto, é fundamental avaliar a percepção dos visitantes, visto que esta se altera com as gerações, nível de escolaridade, conhecimento sobre os animais, importância e função dos zoológicos na conservação das espécies e práticas mais eficazes de entretenimento do público frequentador (MENDES, 2014; ARAGÃO; KAZAMA, 2014).

A percepção dos visitantes sobre questões ambientais pode auxiliar os zoológicos sobre o desenvolvimento de métodos que tenham como objetivo educar sobre o bem-estar animal e a efetiva conservação faunística. Dessa forma, este trabalho tem como objetivo identificar a percepção dos visitantes de parques zoológicos de Santa Catarina sobre a conservação ex situ, ao longo de uma série temporal não antes estudada.

Essa caracterização dos visitantes poderá subsidiar a definição de estratégias de EA direcionadas, despertando maior atenção e preocupação em relação ao grave problema da extinção de espécies, além de orientar o setor responsável pelos programas educativos ambientais. Afinal, a maneira como os visitantes percebem o ambiente do zoológico, com críticas e ideias sobre questões ambientais e conservação, são importantes e ajudam a reaproximar o ser humano da natureza, garantindo um futuro com mais qualidade de vida para todos (AURICCHIO, 1999).

\section{Dos locais pesquisados}

A presente pesquisa abrangeu quatro instituições zoológicas existentes no Estado de Santa Catarina: 1) o Complexo Ambiental Parque Cyro Gevaerd Zoo (PCG Zoo); 2) a Fundação Parque Ecológico Zoobotânico de Brusque (Zoobotânico); 3) a Fundação Hermann Weege (Zoo Pomerode); e, 4) Zoológico de Beto Carrero World (Zoo BCW).

\subsection{Complexo Ambiental Parque Cyro Gevaerd Zoo (PCG Zoo) ${ }^{5}$}

Localizado às margens da BR 101, em Balneário Camboriú (SC), o Parque da Fauna, Flora e Gea foi inaugurado em $1^{\circ}$ de dezembro de 1981, visando atender o fluxo de turistas no litoral catarinense. Constituído por aproximadamente 1.100 animais, distribuídos em 126 espécies de aves, 18 de mamíferos e 16 de répteis, o parque conta ainda com Aquário e Museus (arqueológico, oceanográfico, de taxidermia, artesanato catarinense e do pescador), Núcleo de Educação Ambiental (NEA) e Berçário.

Atualmente, o PCG Zoo é administrado pelo Instituto Catarinense de Conservação da Fauna e Flora (ICCO), através da assinatura do Contrato de Gestão com o Governo do Estado de Santa Catarina e a Agência de Desenvolvimento do Turismo de Santa Catarina (SANTUR), em 2007.

\subsection{Fundação Parque Ecológico Zoobotânico de Brusque (Zoobotânico) ${ }^{6}$}

A Fundação Ecológica e Zoobotânica de Brusque (Parque Ecológico e Zoobotânico Padre Raulino Reitz) foi criada em 1991, e inaugurada em setembro de 1992. O Zoobotânico conta com um complexo de $120.000 \mathrm{~m}^{2}$, onde estão expostos cerca de 180 animais de 60 espécies, abrangendo répteis, aves e mamíferos, naturais da região e exóticas ${ }^{7}$.

\footnotetext{
${ }^{5}$ Informações retiradas do sítio eletrônico da instituição. Disponível em http://www.zoobalneariocamboriu.com.br/historico/\#a. Acessado em 22/10/2019.

${ }^{6}$ Informações retiradas do sítio eletrônico da instituição. Disponível em https://portal.brusque.sc.gov.br/fundacao/parque-zoobotanico/. Acessado em 22/10/2019.

${ }^{7}$ Informação retirada do facebook da instituição, em 15 de fevereiro de 2019.
} 
Administrado pelo Poder Público Municipal de Brusque, atende cerca de 40.000 alunos por ano, provenientes do município, outras regiões do estado e país, promovendo educação ecológica informal, que visa o despertar da consciência para o papel do indivíduo no contexto ambiental que o envolve.

\subsection{Zoológico de Beto Carrero World (Zoo BCW $)^{8}$}

Nascido junto com o Parque Multitemático, em 1991, o Zoológico de Beto Carrero World foi uma das primeiras áreas criadas dentro do $\mathrm{BCW}$, sendo, atualmente, um dos locais mais modernos e adaptados do lugar.

O Zoo BCW abriga cerca de mil animais, sendo 118 mamíferos, 877 aves e 48 répteis, visando a preservação da fauna brasileira e a conscientização dos visitantes sobre a importância dos animais.

\subsection{Fundação Hermann Weege (Zoo Pomerode) ${ }^{9}$}

O Zoo Pomerode foi fundado em 1932, constituindo-se no primeiro zoológico na região sul do Brasil e a primeira iniciativa privada de conservação de fauna no país, além do maior zoológico de Santa Catarina.

Possuindo $35.000 \mathrm{~m}^{2}$ de área construída e mais $65.000 \mathrm{~m}^{2}$ destinados a futuras ampliações, abriga cerca de 1.011 animais distribuídos em 242 espécies, muitas em risco de extinção na natureza.

O Zoo Pomerode tem procurado motivar ações que possam contribuir na melhoria da qualidade ambiental através do NEA Hans Eduard Arnhold, que procura sensibilizar e conscientizar os visitantes que os problemas ambientais são fruto de uma relação desequilibrada entre a natureza e a sociedade.

\section{Dos procedimentos metodológicos aplicados}

Para analisar as percepções dos visitantes de parques zoológicos de Santa Catarina foram utilizados os dados pertencentes ao Laboratório de Biologia, da Escola do Mar Ciência e Tecnologia, da Universidade do Vale do Itajaí (UNIVALI). Também foram realizadas análises de notícias veiculadas na rede mundial de computadores através da ferramenta google alerts e observação não participante nos parques zoológicos pesquisados durante os anos de 2016 a 2019.

Os dados primários provenientes de entrevistas semiestruturadas (questionários), foram agrupados de acordo com o esforço amostral nos zoológicos. Na formação do Grupo 1 foram utilizados dados coletados em 2000, nos quatro zoológicos: PCG Zoo, Zoo BCW, Zoobotânico e Zoo Pomerode. O Grupo 2 foi estruturado com dados de 2007 a 2015, obtidos no Zoo Pomerode. Já o Grupo 3 contém os dados de 2016 e 2017, coletados apenas no Zoobotânico e Zoo Pomerode, devido à falta de autorização das direções dos zoológicos PCG Zoo, Zoo BCW para entrevistar visitantes nesses anos. Assim, constitui-se uma linha temporal das percepções durante o período de 2009 a 2019.

\footnotetext{
${ }^{8}$ Informações retiradas do sítio eletrônico da instituição. Disponível em https://casadoturista.com.br/zoo-betocarrero-world/. Acessado em 22/10/2019.

${ }^{9}$ Informações retiradas do sítio eletrônico da instituição. Disponível em https://www.pomerzoo.org.br/oZoo.php. Acessado em 22/10/2019.
} 
Paralelamente, foram realizadas visitas semestrais às instituições para observação não participante e acompanhamento dos Programas Educativos Ambientais (PEA) e projetos correlatos. Durante as observações realizadas no Zoo Pomerode e Parque Zoobotânico de Brusque (Grupo 3), nos anos de 2016 e 2017, os visitantes foram indagados ainda sobre bemestar animal e enriquecimento ambiental.

A quantidade de questionários aplicados variou de acordo com os anos de coleta, mas a estrutura manteve-se a mesma (Anexo 01). No total foram aplicados 2.178 questionários com visitantes dos quatros parques zoológicos amostrados entre 2000 a 2017 (Tabela 1).

Tabela 1 - Número de questionários aplicados sinalizando os grupos formados de acordo com o esforço amostral realizado e a série temporal analisada.

\begin{tabular}{cccccccc}
\hline \multirow{2}{*}{ INSTITUIÇÃO } & GRUPO 1 & \multicolumn{3}{c}{ GRUPO 2 } & \multicolumn{3}{c}{ GRUPO 3 } \\
\cline { 2 - 8 } & $\mathbf{2 0 0 0}$ & $\mathbf{2 0 0 7}$ & $\mathbf{2 0 1 1}$ & $\mathbf{2 0 1 2}$ & $\mathbf{2 0 1 5}$ & $\mathbf{2 0 1 6}$ & $\mathbf{2 0 1 7}$ \\
\hline PCG Zoo & 455 & - & - & - & - & - & - \\
Zoobotânico & 404 & - & - & - & - & 44 & 22 \\
Zoo BCW & 535 & - & - & - & - & - & - \\
Zoo Pomerode & 473 & 49 & 30 & 60 & 20 & 69 & 16 \\
\hline \multicolumn{7}{c}{ Fonte: Elaboração dos autores }
\end{tabular}

Para caracterizar a percepção dos visitantes foram abordadas: i) as razões para a existência de um zoológico, ii) suas características desejáveis, iii) os motivos da visitação, iv) meios de comunicação para a disseminação das informações, além da idade e gênero dos visitantes.

Utilizou-se, também, a ferramenta google alerts para o recebimento de notícias veiculadas sobre Zoológicos, Enriquecimento Ambiental e Bem-estar Animal, no período compreendido entre 27 de outubro de 2016 e 04 de agosto de 2019.

Para a análise dos dados foi organizada matriz de resposta de presença e ausência (0/1), onde se aplicou o coeficiente de similaridade Jaccard para todos os questionários dentro dos grupos estabelecidos. A similaridade entre os grupos foi analisada por meio da Permanova, aplicada considerando os grupos como fator. Para aqueles que foram considerados significativos foram calculadas as contribuições das respostas para a similaridade média dentro dos grupos. Essas similaridades foram representadas por meio do dendrograma (CLARKE; WARWICK, 1994; ANDERSON 2001).

\section{Resultados e discussão}

A maior parte dos 2.178 visitantes dos parques zoológicos pesquisados foi identificada como sendo do sexo feminino (54,2\%), com idade entre 12 e 20 anos (34,6\%), considerando todos os anos pesquisados (Tabela 2). Essa dominância se manteve em todos os grupos pesquisados.

Tabela 2 - Perfil dos visitantes considerando as variáveis sexo e idade.

\begin{tabular}{cccccc}
\hline & & GRUPO 1 & GRUPO 2 & GRUPO 3 & TODOS DADOS \\
\hline \multirow{2}{*}{ SEXO } & Feminino & 53,5 & 58,7 & 58,3 & 54,2 \\
& Masculino & 46,5 & 41,3 & 41,7 & 45,8 \\
\hline \multirow{4}{*}{ IDADE } & $\mathbf{1 2 - 2 0}$ & 37,4 & 25,0 & 9,3 & 34,6 \\
& $\mathbf{2 1 - 3 0}$ & 29,7 & 25,6 & 33,8 & 29,7 \\
& $\mathbf{3 1 - 4 0}$ & 21,3 & 27,5 & 24,5 & 21,9 \\
& $\mathbf{4 1 - 5 0}$ & 8,1 & 12,5 & 20,5 & 9,3 \\
& $\mathbf{5 1 - 6 0}$ & 2,5 & 5,0 & 6,6 & 3,0 \\
& $\mathbf{6 1 - 7 0}$ & 0,8 & 3,1 & 4,6 & 1,2 \\
& $\mathbf{7 1}$ & 0,2 & 1,3 & 0,7 & 0,3 \\
\hline
\end{tabular}


Fonte: Elaboração dos autores

Já com relação à idade, verificou-se uma flutuação considerando os grupos analisados, abrangendo 37,4\% entre 12 e 20 anos (Grupo 1), 27,5\% de 31 e 40 anos (Grupo 2) e 33,8\% de 21 a 30 anos (Grupo 3).

A permanova indicou diferenças significativas entre os grupos (Tabela 3), sendo todos significativamente diferentes (Tabela 4).

Tabela 3 - PERMANOVA aplicada no Grupo 1, considerando o fator local.

\begin{tabular}{lcccccc}
\hline Source & df & SS & MS & Pseudo-F & P(perm) & Unique perms \\
\hline Lo & 3 & $1,3542 \mathrm{E} 5$ & 45138 & 15,93 & 0,001 & 999 \\
Res & 1863 & $5,2789 \mathrm{E} 6$ & 2833,6 & & & \\
Total & 1866 & $5,4144 \mathrm{E} 6$ & & & & \\
\hline
\end{tabular}

Fonte: Elaboração dos autores

A estrutura das instituições, atividades e programas desenvolvidos, bem como o próprio processo de gestão podem interferir na percepção dos visitantes, gerando essa diferença significativa entre os locais pesquisados. Em seguida, as similaridades foram testadas após a aplicação da ferramenta pair-wise tests, obtendo-se os resultados apresentados na Tabela 4.

Tabela 4 - Resultado do pair-wise test para o fator local

\begin{tabular}{lccc}
\hline \multicolumn{1}{c}{ Groups } & T & P(perm) & Unique Perms \\
\hline Zoo Pomerode, Zoo BCW & 4,1329 & 0,001 & 998 \\
Zoo Pomerode, PCG Zoo & 3,4692 & 0,001 & 998 \\
Zoo Pomerode, Zoobotânico & 1,7557 & 0,001 & 997 \\
Zoo BCW, PCG Zoo & 5,9631 & 0,001 & 999 \\
Zoo BCW, Zoobotânico & 3,3349 & 0,001 & 999 \\
\hline
\end{tabular}

Fonte: Elaboração dos autores

O lazer como motivo de visitação foi o que mais contribuiu para Zoo Pomerode, BCW e Zoobotânico, enquanto observação dos animais para PCG Zoo (Tabela 5).

Tabela 5 - Níveis de similaridade para a formação dos subgrupos formados na análise do Grupo 1

\begin{tabular}{cccc}
\hline Zoo Pomerode & Zoo BCW & PCG Zoo & Zoobotânico \\
\hline Average similarity & Average similarity & Average similarity 27,04\% & $\begin{array}{c}\text { Average similarity } \\
27,71 \%\end{array}$ \\
\hline $24,84 \%$ & $29,77 \%$ & & OBSmv 24,30\% \\
LAZmv 12,81\% & LAZmv 28,56\% $17,65 \%$ \\
TVmi 12,68\% & $12-2015,84 \%$ & $12-2012,86 \%$ & TVmi 12,89\% \\
CONSez 12,28\% & CONSez 13,38\% & CONSez 10,41\% & CONSez 12,14\% \\
OBSmv 10,00\% & & & $21-307,90 \%$ \\
$21-309,17 \%$ & & & \\
\hline
\end{tabular}

Legenda: LAZmv - visita para lazer; OBSmv - visita para observação de animais; CONSez - Conservação das espécies como razão da existência dos zoológicos; TVmi - Televisão aberta como meio de informação; Grupos etários: $12-20$ e 21-30.

Fonte: Elaboração dos autores

Observa-se que os aspectos que deveriam estar presentes em um zoológico ideal não contribuíram para o estabelecimento dos grupos, aparecendo apenas como importante fator de contribuição para o Zoo BCW, no ano de 2000. O lazer como motivo de visita se sobrepõe a outros motivos para o Zoo Pomerode, Zoobotânico e Zoo BCW, destacando-se, também, quando analisamos todos os dados coletados ao longo do tempo (Figura 1). As faixas etárias de maior contribuição para o ano de 2000 abrangem 12 a 30 anos, tendo variado nas contribuições 
dos locais estudados. Para o ano de 2000, a TV aberta contribuiu para a similaridade de todos os zoológicos, tendo sido complementada pela comunicação realizada no próprio zoológico apenas para o PCG Zoo, onde a observação se destacou como motivo da visita.

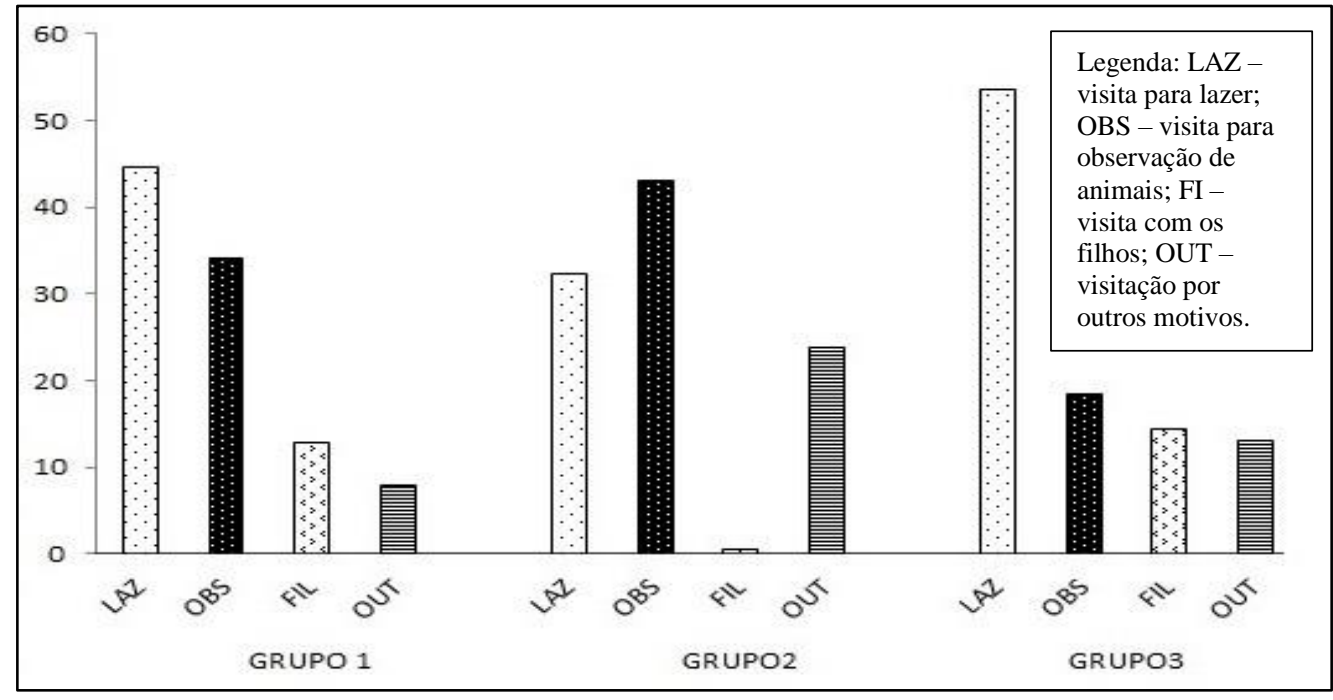

Figura 1 - Motivo de visita a um zoológico. Fonte: Elaboração dos autores

O Grupo 2, composto pelo período de 2007 a 2015, apresentou diferença significativa (PERMANOVA, $\mathrm{p}=0,021$ ). Quando verificado se ocorria diferença entre anos específicos pelo pair-wise tests, foram obtidos valores significativos quando comparados os anos de 2015 2007, 2015 e 2012 (Tabela 6).

Tabela 6 - Resultado do pair-wise test para o fator ano

\begin{tabular}{cccc}
\hline Groups & $\mathbf{t}$ & $\mathbf{P}($ perm) & Unique Perms \\
\hline 2015,2007 & 1,5728 & 0,006 & 998 \\
2015,2011 & 1,3525 & 0,065 & 999 \\
2015,2012 & 1,5051 & 0,011 & 998 \\
2007,2011 & 1,0205 & 0,412 & 996 \\
2007,2012 & 1,2517 & 0,103 & 999 \\
\hline \multicolumn{5}{c}{ Fonte: Elaboração dos autores }
\end{tabular}

Analisando a contribuição das respostas para a similaridade média dentro dos anos foi possível verificar que, entre os anos que foram diferentes (2007-2012-2015), o lazer contribuiu mais para 2007, a categoria outros para 2012 e a observação para 2015 (Tabela 7).

Tabela 7 - Níveis de similaridade para a formação dos subgrupos formados na análise do GRUPO 2.

\begin{tabular}{cccc}
\hline $\mathbf{2 0 0 7}$ & $\mathbf{2 0 1 1}$ & $\mathbf{2 0 1 2}$ & $\mathbf{2 0 1 5}$ \\
\hline Average similarity & Average similarity & Average similarity & Average similarity \\
$23,28 \%$ & $25,24 \%$ & $24,79 \%$ & $29,89 \%$ \\
\hline LAZmv $15,34 \%$ & OBSmv $24,77 \%$ & OUTmi $19,18 \%$ & OBSmv $19,37 \%$ \\
OBSmv $12,49 \%$ & OUTmi $14,21 \%$ & OBSmv $10,19 \%$ & $12-2012,68 \%$ \\
$21-309,93$ & $31-406,56 \%$ & LAZmv $9,26 \%$ & RRZi $12,68 \%$ \\
TVmi $8,77 \%$ & LAZez 6,56\% & $31-406,75 \%$ & NETmi $12,68 \%$ \\
OUTmi $7,67 \%$ & OUTmv 6,75\% & \\
\hline
\end{tabular}

Legenda: LAZmv - visita para lazer; OBSmv - visita para observação de animais; CONSez - Conservação das espécies; TVmi - Televisão aberta como meio de informação; grupos etários: 12-20, 21-30 e 31-40; LAZez - Zoo para lazer; NETmi - Internet como meio de informação; RRZi - zoológico para reprodução e reintrodução de espécies; OUTmi - outros meios de informação; OUTmv - visitação por outros motivos. 
Chama atenção a razão para a existência do zoológico que auxiliou na formação do grupo do ano de 2015, que não havia configurado similaridade para os anos anteriores. A reprodução e a reintrodução das espécies surgem nas respostas dos visitantes, possivelmente como reflexo da divulgação de programas como o do mico-leão-dourado (Leontopithecus rosalia), peixe-boi (Trichechus manatus) e do projeto TAMAR, utilizando a internet como maior meio de comunicação das ações realizadas e dos níveis de sucesso alcançados ano após ano. Em 2011, por exemplo, foi reintroduzido, na base avançada de Porto de Pedras, litoral norte de Alagoas ${ }^{10}$, o primeiro peixe-boi nascido em cativeiro no Brasil. Nessa época, os zoológicos, como o Zoo Pomerode, também começaram a divulgar, com maior intensidade, as atividades desenvolvidas por eles em programas específicos de reprodução e reintrodução das espécies, como a do mico-leão-da cara-dourada (Leontopithecus chrysomelas) e a já citada $L$. rosalia.

Como meio de informação mais adequado para abordar assuntos relacionados à conservação animal e do meio ambiente verificou-se a evolução da TV aberta para a internet, com o conjunto deles (caracterizado dentro de OUTmi) para os anos de 2011 e 2012, como uma transição nos processos de comunicação, com apontamentos maiores para a TV aberta, em 2007, e maiores para a internet, em 2015, contribuindo substancialmente com a similaridade presente no ano de 2015 (Figura 2).

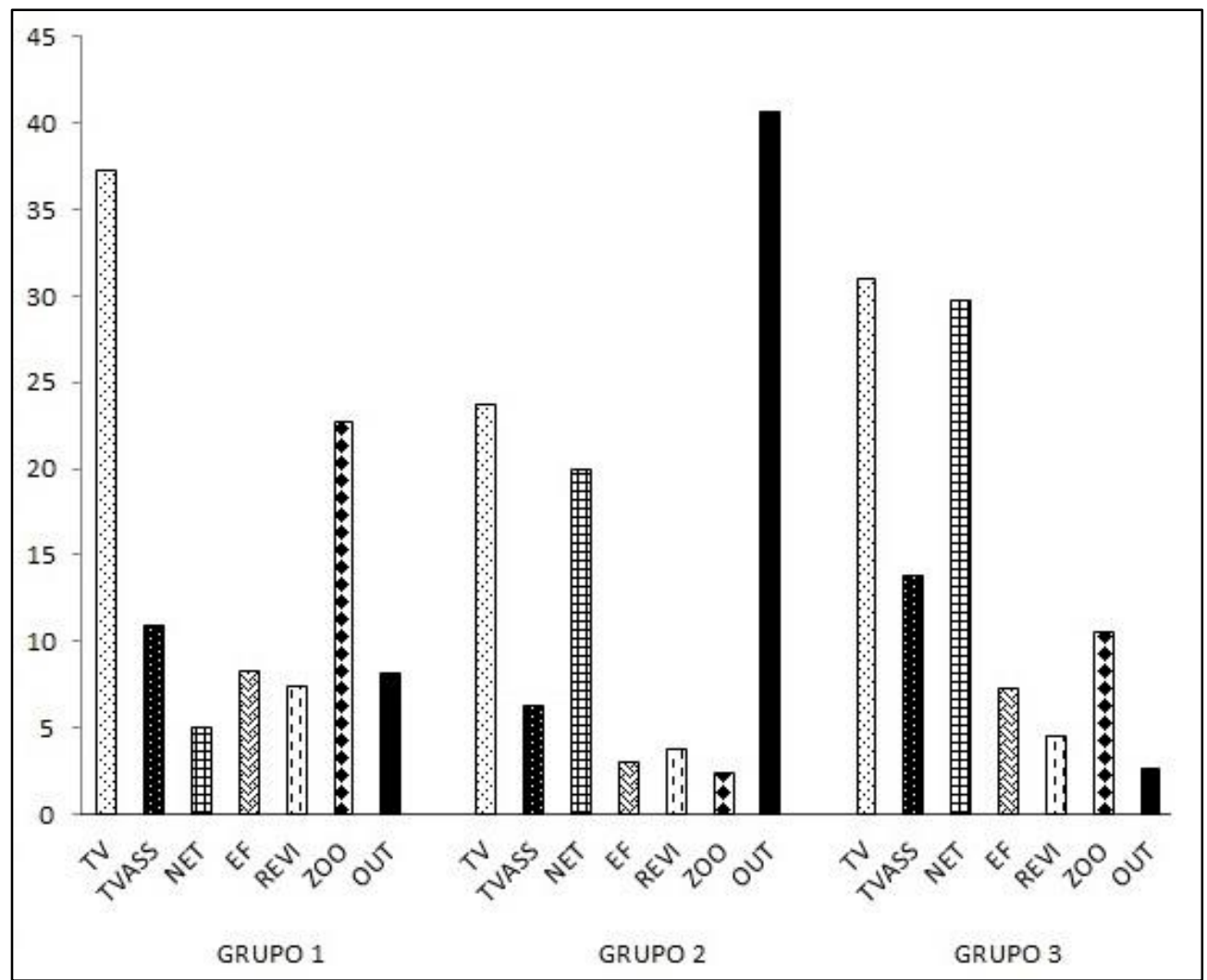

Legenda: TV - Televisão aberta como meio de informação; TVASS - Canais por assinatura como meio de informação; NET - Internet como meio de informação; EF - Ensino formal como meio de informação; REVI - Revistas e Jornais específicos como meio de informação; ZOO - zoológico como meio de informação; OUT - outros meios de informação.

${ }^{10}$ Primeiro peixe-boi nascido em cativeiro no Brasil ganha liberdade. O Globo. 03/04/2011. Disponível em https://oglobo.globo.com/brasil/primeiro-peixe-boi-nascido-em-cativeiro-no-brasil-ganha-liberdade-2801989. Acesso em 16 out. 2019. 
Figura 2 - Série temporal dos meios de comunicação para os grupos pesquisados Fonte: Elaboração dos autores

O Grupo 3, formado pelo Zoobotânico e Zoo Pomerode, nos anos de 2016 e 2017, apresentou diferença significativa para o fator ano $(\mathrm{p}=0,001)$, não apresentando diferença para os locais estudados $(\mathrm{p}=0,194)$. Porém, quando analisada a interação entre os fatores apresentou diferença significativa $(\mathrm{p}=0,015)$ (Tabela 8$)$.

Tabela 8 - PERMANOVA aplicada ao GRUPO 3, considerando os fatores ano e local

\begin{tabular}{cccccc}
\hline Source & df & SS & MS & Pseudo-F & Unique P(perm) \\
\hline An & 1 & 10587 & 10587 & 3,6371 & 0,001 \\
Lo & 1 & 3895,4 & 3895,4 & 1,3382 & 0,194 \\
AnxLo & 1 & 6134,8 & 6134,8 & 2,1075 & 0,015 \\
\hline
\end{tabular}

Fonte: Elaboração dos autores

As similaridades existentes entre os zoológicos, nos anos estudados, são apresentadas na Tabela 9.

Tabela 9 - Níveis de similaridade para a formação dos subgrupos formados na análise do Grupo 3

\begin{tabular}{cccc}
\hline & $\mathbf{2 0 1 6}$ & & \multicolumn{2}{c}{$\mathbf{2 0 1 7}$} & \\
\hline Zoo Pomerode & Zoobotânico & Zoo Pomerode & Zoobotânico \\
\hline Average similarity & Average similarity & Average similarity & Average similarity \\
26,73 & 28,71 & 24,00 & 18,67 \\
\hline \multirow{2}{*}{ LAZmv 31,57 } & LAZmv 20,32 & OBSmv 19,44 & FAZmv 13,35 \\
$21-30$ 9,57 & TVmi 11,27 & NETmi 19,44 & 31 -40 9,28 \\
CONSez 8,07 & $21-3010,01$ & OUTzi 14,58 & CONSez 6,57 \\
& REFez 10,01 & & EAez 6,57 \\
\hline
\end{tabular}

filhos; CONSez - zoo para conservação das espécies; TVmi - Televisão aberta como meio de informação; NETmi - internet como meio de informação; Grupos etários: 21-30 e 31-40; EAez - zoo para Educação Ambiental; REFez - refúgio de animais que não podem mais voltar à natureza.

Fonte: Elaboração dos autores

O Zoo Pomerode apresentou lazer como motivo da visita com maior contribuição para os anos de 2016 e 2017, juntamente com o Zoobotânico para o ano de 2017. Apenas no ano de 2017, no Zoo Pomerode, a observação como motivo da visita apresentou maior contribuição.

O cluster gerado envolvendo os Grupos 1, 2 e 3, nos períodos e instituições amostradas, mostrou a formação de grupos distintos, onde o mais similar agrupou os visitantes de 12 a 20 anos (Figura 3). 


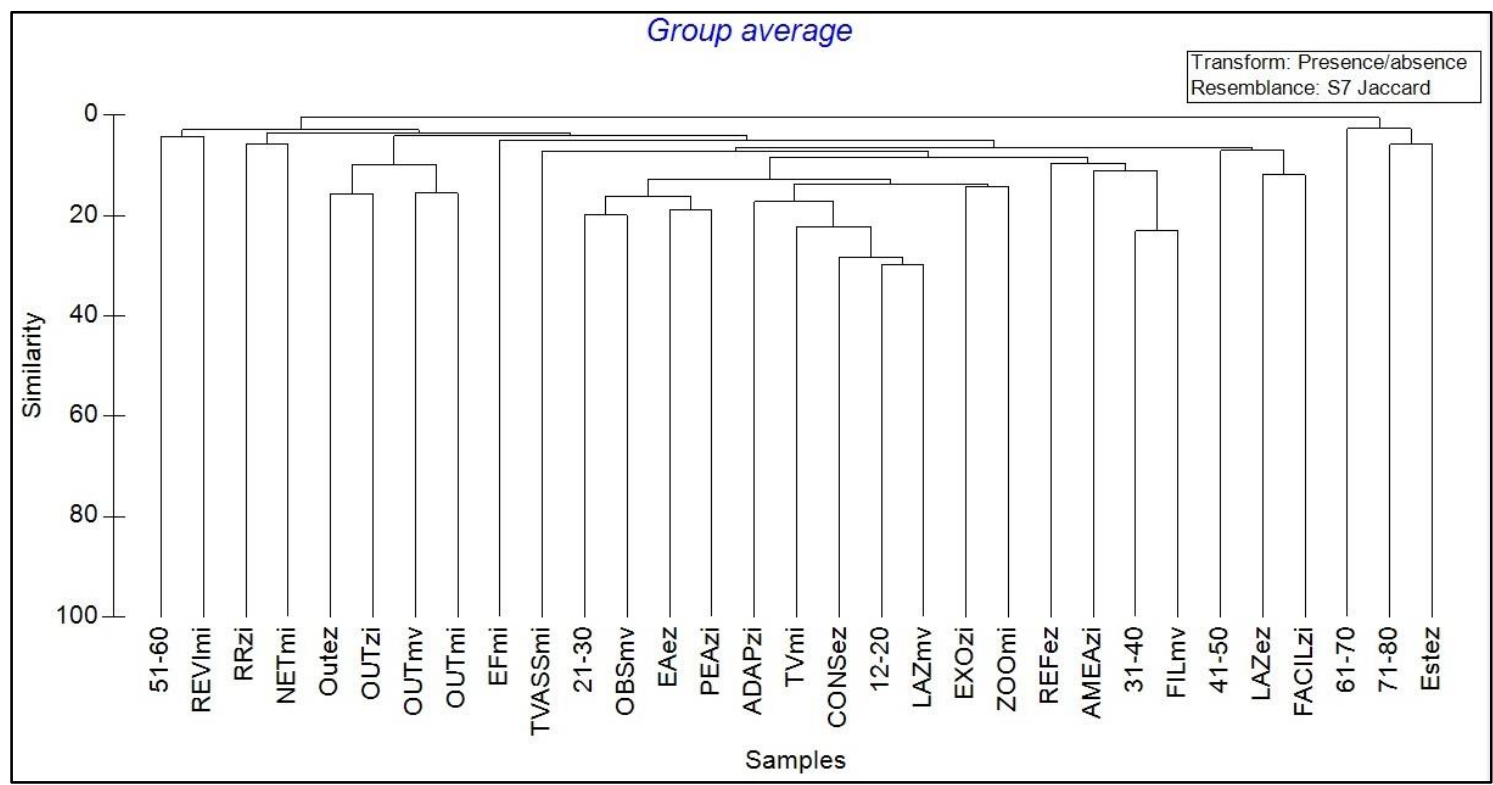

Legenda: Motivo da visita: LAZmv - visita para lazer; OBSmv - visita para observação de animais, FILmv - visita com os filhos; OUTmv - visitação por outros motivos; Razão da existência dos zoológicos: CONSez - zoo para conservação das espécies, LAZez - zoo para lazer, EAez - zoo para Educação Ambiental, ESTez - zoo para estudos e pesquisa, REFez - zoo como refúgio de animais que não podem mais voltar à natureza, OUTez - outros motivos para existência dos zoológicos; Zoológico ideal: ADAPzi - com animais adaptados, AMEAzi - com espécies ameaçadas de extinção, FACILzi - com animais que sejam fáceis de visualizar, PEAzi - com programas educativos ambientais estruturados, EXOzi - com animais exóticos, RRzi - com programas de reprodução e reintrodução de espécies; Meios de informação: TVASSmi - Canais por assinatura como meio de informação, NETmi - Internet como meio de informação, TVmi - Televisão aberta como meio de informação, EFmi - Ensino formal como meio de informação, REVImi - Revistas e Jornais específicos como meio de informação, ZOOmi - zoológico como meio de informação, OUTmi - outros meios de informação; Grupos etários: 12-20, 21-30, 31-40, 41-50, 51-60, 61-70, $71-80$.

Figura 3 - Cluster gerado com todos os dados coletados no período de 2000 a 2017 nos zoológicos pesquisados Fonte: Elaboração dos autores

A faixa etária esteve associada a percepções dos visitantes de zoológicos em 2000, onde os visitantes de 12 a 20 anos procuram os zoológicos como um local de lazer, acreditam que a razão da existência dessas instituições seja para conservação dos animais e que o zoológico ideal é aquele onde os animais encontram-se mais adaptados.

Os visitantes de 21 a 30 anos acreditam que o zoológico é o espaço adequado para o desenvolvimento da EA, onde a observação dos animais é o motivo de visita. Assim, um zoológico ideal para esse grupo é aquele que apresenta programas e projetos educativos ambientais.

Já os visitantes entre 31 a 40 anos utilizam os zoológicos para levar os filhos, pois os consideram refúgios para animais que não podem mais retornar a natureza. Assim, têm como zoológico ideal os que possuem apenas animais ameaçados de extinção no plantel.

Para as pessoas de 41 a 50 anos, os zoológicos existem como espaços de lazer, com facilidade em ver os animais. Um quinto grupo, formado por visitantes de idades diversas, indicou outros motivos (geralmente atrelado aos filhos e à observação em conjunto), para as razões de existência do zoo e como seria o zoológico ideal (Tabela 10). 
Tabela 10 - Grupos formados através da análise do cluster gerado com todos os dados, considerando os quatro zoológicos pesquisados, no período compreendido entre 200 e 2017

\begin{tabular}{cccc}
\hline \multirow{2}{*}{ IDADE } & MOTIVO DA & RAZÃO DA EXISTÊNCIA DO & \multirow{2}{*}{ ZOO IDEAL } \\
& VISITA & ZOO & Com animais adaptados \\
12 a 20 & Lazer & Conservação & Com PEA \\
21 a 30 & Observar animais & Fazer EA & Com animais ameaçados \\
31 a 40 & Trazer os filhos & Refugio de animais & Facilidade de visualização \\
41 a 50 & Outros & Lazer & . \\
\hline
\end{tabular}

Fonte: Elaboração dos autores

A caracterização do segundo grupo, com idade entre 21 e 30 anos, demonstra a existência dos visitantes nascidos junto com as Políticas de Educação Ambiental, no final da década de 90, e que tiveram na inserção do tema Educação Ambiental nas discussões ambientais maior familiaridade e afinidade com o passar dos anos. Afinal, a EA teve sua Política Nacional estabelecida em 1999, através da Lei № 9.795. No ano de 2005, foi criado o Programa Nacional de Educação Ambiental (ProNEA), resultado de diversas consultas públicas realizadas no ano de 2004, envolvendo mais de oitocentos educadores ambientais de 22 unidades federativas do país ${ }^{11}$. No mesmo ano, em nível estadual, Santa Catarina decretou a Lei № 13.558/2005.

O sétimo princípio da educação para sociedades sustentáveis e responsabilidade global, presente no ProNEA, afirma que

\begin{abstract}
A educação ambiental deve tratar as questões globais críticas, suas causas e interrelações em uma perspectiva sistêmica, em seu contexto social e histórico. Aspectos primordiais relacionados ao desenvolvimento e ao meio ambiente, tais como população, saúde, paz, direitos humanos, democracia, fome, degradação da flora e fauna, devem ser abordados dessa maneira (MMA, 2005, p. 58).
\end{abstract}

Nesse sentido, apesar de as instituições zoológicas não serem citadas diretamente nos documentos legais sobre a EA, sabe-se que como espaço não formal para o desenvolvimento de programas, projetos e ações educativas ambientais é riquíssimo, possuindo grande potencial de multiplicação e disseminação de conhecimentos, como uma sala de aula viva (MERGULHÃ̃O, 1998). O termo espaços não formais de educação vem sendo utilizado de forma ampla por diversos pesquisadores na área de educação científica, como sendo qualquer espaço diferente da escola onde seja possível desenvolver atividades educativas (JACOBUCCI, 2008).

Os zoológicos possuem potencial pedagógico próprio, uma vez que o carisma, beleza, fascínio e curiosidade pela vida animal despertam nos indivíduos a busca por uma melhor compreensão da natureza (MENEGAZZI, 2003). Esses espaços, como ambiente educativo não formal, estimulam o público a aprender mais sobre os animais e seu meio ambiente (ACHUTTI; BRANCO, 2003), fazendo refletir sobre educação, lazer e cidadania, gerando novas atitudes sobre conservação ambiental (CHRISTOFFERSEN; BRANCO; FURTADO, 2013; LUTTERBACH; MENEGAZZI, 1998). Além disso, os espaços formais para EA realizam atividades integradas aos zoológicos, fazendo com que a sensibilização e conscientização ambiental para a conservação de espécies nativas e exóticas, in situ e ex situ, seja efetivamente ampliada. Ressalta-se essa questão, justamente, pela presença de programas e ações educativas ambientais específicas identificadas nos zoológicos pesquisados através de seus sítios eletrônicos ${ }^{12}$.

\footnotetext{
${ }^{11}$ MMA. Programa Nacional de Educação Ambiental - ProNEA / Ministério do Meio Ambiente, Diretoria de Educação Ambiental; Ministério da Educação. Coordenação Geral de Educação Ambiental. - 3. ed - Brasília : Ministério do Meio Ambiente, 2005. 102p.: il. $21 \mathrm{~cm}$.

${ }^{12}$ Levantamento finalizado em outubro de 2019, através das informações disponibilizadas os sítios eletrônicos das instituições pesquisadas.
} 
$\mathrm{O}$ Zoo BCW é destinado à proteção, amparo e conservação de centena de espécies de animais, conforme informação disponibilizada em seu website. Porém, não há referências a programas educativos ambientais específicos, apenas à existência de monitores para as atividades ali desenvolvidas. Furtado (2002) já sinalizava o grande potencial do parque temático, questionando a ausência de programas educacionais atrelados às diversas atrações disponibilizadas pela instituição.

O Zoobotânico sinaliza o programa Educação Ecológica Informal para escolas, com atendimento de 40.000 alunos por ano. Há, também, a realização de visitas noturnas, atividades educativas ambientais em datas comemorativas e a realização de cursos sobre enriquecimento ambiental, onde os visitantes auxiliam na confecção de estruturas alimentares e sensoriais olfativas para a introdução nos recintos. Em 2002, Furtado apontava que o programa educacional resumia-se em monitoramento das visitas de grupos escolares. Observa-se, atualmente, um grande fluxo de informações disponibilizadas nas redes sociais da instituição, abordando o dia-a-dia no parque e os hábitos e costumes de diversos animais.

Já o Zoo Pomerode apresenta, atualmente, dez projetos de EA, destacando o projeto Embaixadores da Biodiversidade, caracterizado por visitas pedagógicas guiadas. Também, apresentam eventos específicos relacionados a datas comemorativas ou a eventos de temática específica e relacionados à conservação de fauna.

O desenvolvimento de vídeos (Série Animais) disponibilizados em redes sociais e seu website, o Projeto Arca de Noé que trata da adoção de animais por empresas da região, newsletter, destaques do mês, entre outras ferramentas, também são realizadas pelo Zoo Pomerode. Mais recentemente, foi criado o programa Zoo Responde, disponível nas redes sociais, abordando diversos fatos e informações sobre o funcionamento do parque e o dia-a-dia dos animais, servindo para responder as dúvidas recebidas pelo setor de EA. Segundo Furtado (2002) o Zoo Pomerode não possuía uma logística destinada aos trabalhos educacionais, mesmo possuindo grande fluxo de estudantes. A instituição possui atividades que visam aproximar o público com as atividades de manutenção e cuidados com os animais.

A pressão por atividades educativas ambientais, que permitam maior interatividade com os animais, como a executada pelo Zoo Pomerode, é considerada crescente (PROHNII et al., 2015). O Zoo Pomerode participa de studbooks de diversas espécies presentes no seu plantel ${ }^{13}$. O studbook é um livro de registro de dados genealógicos de uma determinada espécie animal, apresentando valiosas informações para a tomada de decisão acerca do manejo adequado de populações em cativeiro, buscando manter a variabilidade genética máxima dos indivíduos de diversas espécies sob cuidados humanos. A divulgação desse conhecimento e dos programas que relacionam a variabilidade genética dessas populações pode auxiliar na ampliação da percepção e do entendimento das funções atuais dos zoológicos e busca garantir, efetivamente, a conservação ex situ pretendida.

O PCG Zoo estabelece a EA realizada para a observação, o estudo e a sensibilização dos visitantes. Existe um NEA definido e divulgado em seu website. Projetos EA no Zôo e Me Adote (seja um amigo do zôo) também são divulgados amplamente, assim como outras informações por newsletter e destaques do mês. O PCG Zoo havia sido apontado por Furtado (2002), como sendo o zoológico que possuía o projeto de EA mais estruturado, oferecendo, em dezesseis anos de funcionamento, visitas monitoradas, dinâmicas, palestras e minicursos. Também, cabe ressaltar o esforço do PCG Zoo na divulgação da origem dos animais que estão

\footnotetext{
${ }^{13}$ O Zoo Pomerode participa do Studbook do Lobo-guará (Chrysocyon brachyurus), do Mico-leão-da-caradourada (Leontophitecus chrysomelas), do Macaco-aranha-de-testa-branca (Ateles marginatus), do Tamanduábandeira (Myrmecophaga tridactyla), do Tamanduá-mirim (Tamandua tetradactyla), da Anta (Tapirus terrestres) e da Jacutinga $\quad$ (Aburria jacutinga). $\quad$ Disponível em https://www.pomerzoo.org.br/ConservacaoAmbiental.php?id=244. Acesso em 28 out. 2019.
} 
no seu plantel, com o uso intensificado de placas informativas específicas, registradas durante as observações participantes no período de análise.

Todos os zoológicos pesquisados são ligados à Associação de Zoológicos e Aquários do Brasil (AZAB), compondo o grupo de EA, que realiza, anualmente, reuniões e encontros para discutir as diretrizes e caminhos para programas e projetos educativos ambientais nessas instituições e se mantém ativo, cotidianamente, através de grupos de trocas de mensagens ${ }^{14}$. Porém, não identifica-se ainda PEA's que consigam, de fato, abordar as inter-relações no contexto social, histórico e cultural onde os parques estão inseridos geograficamente.

Mesmo sendo considerados lugares apropriados para desenvolver EA, segundo Christoffersen, Branco e Furtado (2013) os zoológicos ainda subutilizam seu potencial na conservação, no desenvolvimento de pesquisas científicas e em programas educativos ambientais.

Bazarra (1994) defende que a EA deve ser incorporada como um processo permanente, dinâmico e integral nos programas dos zoológicos, estudando a inter-relação do indivíduo com seu entorno e proporcionando a construção de uma nova cultura ambiental. A autora menciona alguns objetivos presentes nesse tipo de educação, como: proporcionar conhecimentos científicos, reforçar atitudes positivas, apontar elementos para desenvolvimento de uma consciência ambiental; ressalta, também, algumas vantagens educativas que os zoológicos oferecem, como o fortalecimento e enriquecimento cultural ao trabalhar temas relacionados a espécies nativas e exóticas; o desenvolvimento da atividade científica no indivíduo; o estímulo à criatividade e à imaginação; a criação do sentimento de empatia, respeito e admiração à vida silvestre, entre outras. Dessa forma, os trabalhos de EA implantados nos zoológicos dinamizam as programações e tornam as visitas mais atrativas. Transformar um zoológico, inicialmente visto como lazer, em um projeto educacional, é perceber que a realidade educacional é bem mais complexa nos tempos atuais (FURTADO et al., 2011).

Brito (2012) cita que, por exemplo, o caso de visitas não estruturadas, sem um planejamento norteador, acabam por contribuir para que os resultados não sejam aqueles esperados pelo educador e sua equipe. Segundo os estudos realizados por Fonseca e Oliveira (2011), o zoológico não tem cumprido o seu papel educativo, seu compromisso com a formação do cidadão crítico, ciente dos seus direitos e deveres sociais, capaz de intervir nas discussões sobre as questões ambientais em prol de uma sociedade mais justa e ambientalmente sustentável. Podemos citar, ainda, Souza e Albuquerque (2015), que contrapõem questões éticas e discutem a visão antropocêntrica dos zoológicos, ressaltando as situações constantes de estresse e sofrimento que acabam por impossibilitar a transformação desses espaços em ambientes realmente educadores.

Devido à necessidade de tornar as informações acessíveis ao público visitante, os zoológicos requerem o uso de metodologias educativas e avaliativas próprias (GARCIA; MARANDINO, s.d). Segundo Tomazello e Ferreira (2001) há uma unanimidade entre os autores sobre o papel fundamental da avaliação dos projetos e/ou atividades de EA e sobre a importância do desenvolvimento de instrumentos adequados de avaliação.

Para isso, a Associação Latinoamericana de Parques Zoológicos e Aquários (ALPZA) desenvolveu o Processo de Acreditação, que combina avaliações internas e externas, buscando garantir a excelência dos zoológicos e aquários nas áreas: geral/estrutural, segurança, bem-estar animal, educação e conservação (ALPZA, 2017), aplicando normas ou critérios divididos em

\footnotetext{
${ }^{14} \mathrm{O}$ grupo de Educação Ambiental realizou os últimos encontros no zoológico de Bauru (SP) e no Zoo Pomerode (SC), de maneira restrita aos membros associados à AZAB. Foram solicitadas autorizações para acompanhar as reuniões e encontros, não tendo sido autorizado pela diretoria do referido grupo. Também, foram encaminhados questionários para a obtenção de dados sobre os zoológicos participantes e seus programas educativos ambientais no ano de 2018, mas não houve sucesso no retorno dos dados.
} 
críticos, importantes e desejáveis. Esse protocolo vem servindo de base para a elaboração de protocolo específico de certificação de zoológicos e aquários pela $\mathrm{AZAB}^{15}$.

A educação para a conservação, constituinte do processo de acreditação é tida como:

Um campo da educação, que busca ajudar pessoas de todas as idades a compreender e apreciar os recursos naturais, com um enfoque na conservação de ecossistemas e seus componentes, incentivando as pessoas a agir por conta própria para protegê-los e conservá-los, utilizando-os de maneira responsável e tomando decisões sobre os recursos (ALPZA, 2017, p. 31).

Especificamente na área de educação, o processo de acreditação de zoológicos e aquários da ALPZA, aborda as questões apresentadas no Quadro 1.

\begin{tabular}{|c|c|}
\hline $\begin{array}{l}\text { QUESTÕES } \\
\end{array}$ & PRIORIDADES \\
\hline $\begin{array}{l}\text { A existência de compromisso educativo claramente identificável na filosofia da instituição } \\
\text { O uso de ferramentas aos visitantes para identificar as diferentes espécies em exposição } \\
\text { A participação do setor educativo na concepção de novos recintos ou áreas com potencial } \\
\text { educativo }\end{array}$ & Crítico \\
\hline $\begin{array}{l}\text { A existência de profissional exclusivo para trabalhar a educação em tempo integral } \\
\text { A existência de um programa de educação para a conservação } \\
\text { A avaliação dos programas educativos } \\
\text { A semelhança dos recintos aos habitats naturais das espécies }\end{array}$ & Importante \\
\hline
\end{tabular}

Quadro 1 - Questões abordadas no processo de acreditação de zoológicos e aquários da ALPZA: área temática: Educação (ALPZA, 2017).

Fonte: Elaboração dos autores

Percebe-se, assim, que a avaliação do processo educativo ambiental em zoológicos caracteriza-se como uma das prioridades levantadas pela ALPZA, mas não há indicativos sobre como realizá-la e avaliá-la. Essas dificuldades em avaliar e analisar as repercussões de atividades de EA são reconhecidas por diversos autores devido à abrangência dos temas e dos objetivos, pois educar ambientalmente é educar a partir da concepção de uma realidade complexa, isto é, em que todos os elementos constituintes do ambiente estão em contínua interação (TOMAZELLO; FERREIRA, 2001). As autoras destacam que a avaliação de um projeto educativo ambiental torna-se particularmente difícil, pois os resultados não têm uma relação direta com uma atividade ou com um estudo sobre um tema.

Conforme estabelece a WAZA (2015), os zoológicos e aquários modernos existem para fins de conservação da vida selvagem, EA, conscientização pública, programas de reprodução, captação de recursos, colaboração em pesquisas e parcerias para atingir seus objetivos. Nesse sentido, Mendes (2014), Aragão e Kazama (2014) afirmam que o papel integral dos zoológicos não é bem conhecido pelos entrevistados, onde a maioria desconhece as práticas de pesquisas e conservação nessas instituições. A Figura 4 apresenta os resultados obtidos sobre as principais razoes para a existência dos zoológicos na percepção do público visitante abordado para essa pesquisa.

\footnotetext{
${ }^{15}$ Versão inicial foi apresentada no $43^{\circ}$ Congresso da SZB, realizado de 09 a 11 de março de 2017, em Pomerode, Santa Catarina. Trabalho não publicado até o presente momento.
} 


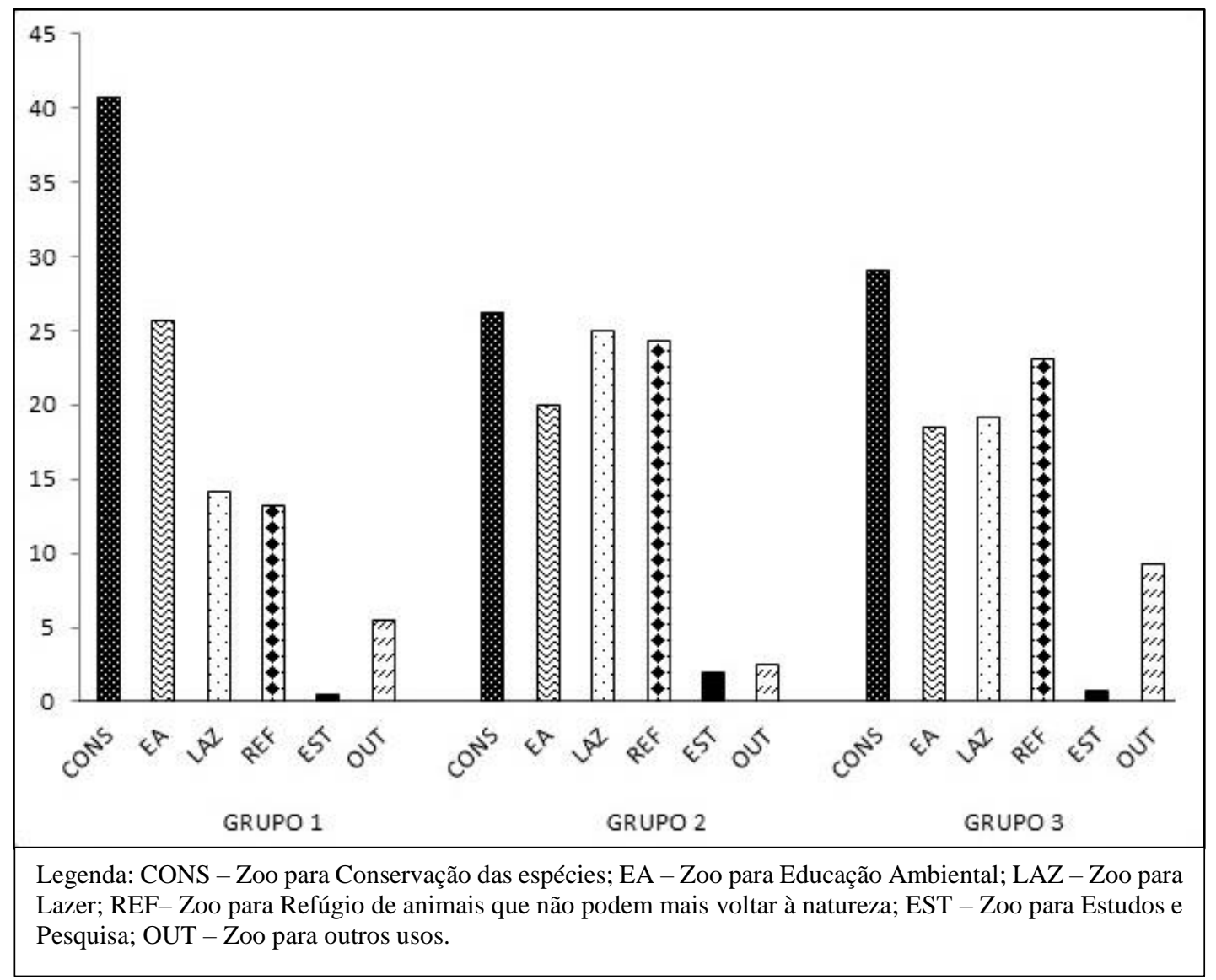

Figura 4 - Série temporal das razões para a existência dos zoológicos para todos os grupos analisados Fonte: Elaboração dos autores

Ao observarmos as respostas sobre a razão que justifique a existência dos zoológicos ao longo dos anos pesquisados, podemos verificar, além da conservação e do lazer pretendido, que a EA possui altos percentuais, mesmo que apresentando variações ao longo dos anos, que acontece para os PEA como constituinte dos zoológicos ideais (Figura 5). Os estudos e pesquisas quase não são citados pelos visitantes pesquisados, onde podemos inferir que ou os visitantes não percebem os zoológicos como espaços propícios à pesquisa ou, realmente, não o reconhecem ainda com tal função. Dias (2003) acredita que poucas instituições são tão propícias à investigação científica como os zoológicos contemporâneos, pois estes criam as condições materiais necessárias para o desenvolvimento de pesquisas nas mais variadas áreas do conhecimento. No inconsciente coletivo a investigação científica ainda não está fortemente presente. 


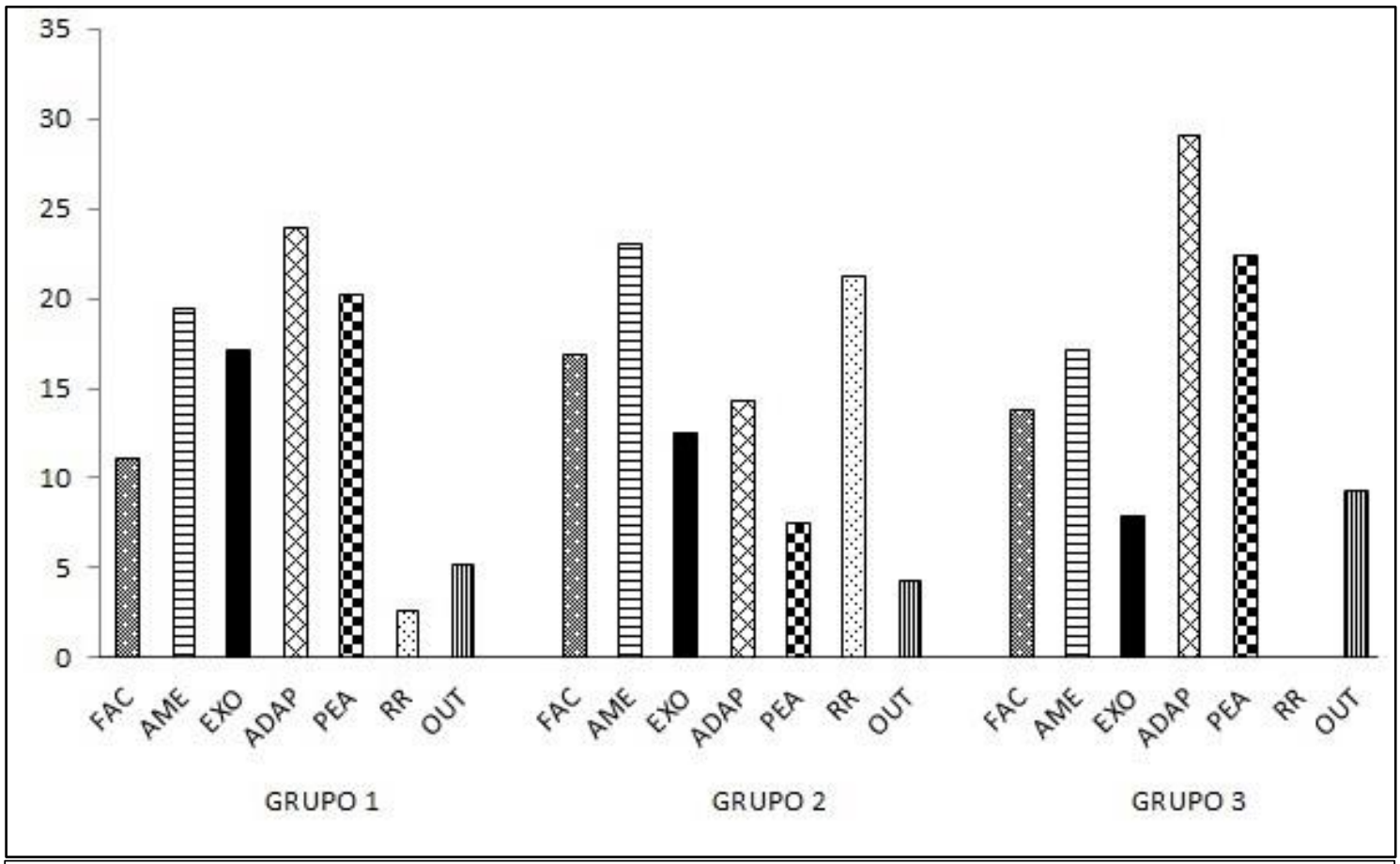

Legenda: FAC - Facilidade em observar o animal; AME - Com animais ameaçados de extinção; EXO - Com animais exóticos; ADAP - Com animais bem adaptados; PEA - Com Programas de Educação Ambiental; RR Com programas de reprodução e reintrodução de espécies; OUT - outros.

Figura 5 - Série temporal dos aspectos que compõem um zoológico ideal para todos os grupos analisados Fonte: Elaboração dos autores

Já sobre um zoológico ideal, a presença de programas específicos de EA destacou-se nos anos de 2000 e 2001, anos em que as conferências mundiais sobre meio ambiente e EA estavam acontecendo e sendo amplamente divulgadas nos meios de comunicação, a exemplo da Conferência Rio+10, realizada em Johanesburgo, África do Sul. Apresentando baixos percentuais entre os anos de 2007 a 2012 e crescendo posteriormente entre os anos de 2012 e 2015, a presença de programas educativos ambientais competiu, posteriormente, nas respostas com os aspectos de adaptação dos animais nos espaços e conservação ex situ e a questão da facilidade em ver esses animais. Essas duas questões, crescentes entre os anos de 2015 a 2017, podem ser consideradas um tanto quanto contraditórias, pois a facilidade em ver um animal ex situ pode estar relacionada a um recinto pouco enriquecido, que poderia estar afetando sua adaptação numa situação de cuidados humanos.

A realidade é que os zoológicos estão deixando de ser apenas um espaço de lazer e passando a adquirir status de arca de Noé do futuro. Ou seja, são uma importante estratégia de conservação de espécies ameaçadas de extinção, que necessitam de grandes áreas para existência, e que estão tendo suas populações drasticamente reduzidas.

Os zoológicos contribuem com temas de EA, conceitos de sustentabilidade e inclusão homem-natureza, buscando cada dia melhorar o condicionamento dos espécimes através do enriquecimento ambiental, procurando despertar no animal seus instintos naturais e no homem um maior interesse pela preservação (SILVA; MACEDO, 2013). Assim, todos os aspectos colocados formam um zoológico ideal, onde existam programas específicos de reprodução e reintrodução de espécies, onde os animais estejam bem adaptados e com o bem-estar animal garantido, onde o público consiga ver facilmente as espécies presentes em cada instituição, sejam elas exóticas ou nativas. O que vai determinar algumas questões específicas é o Plano de Populações de cada instituição, onde esses aspectos devem ser abordados e trabalhados de maneira integrada, para que a instituição zoológica possa ser considerada um espaço educador 
sustentável, como explicam Amaral e Santos (2017, p. 120): “Os espaços educadores, atualmente podem ser conceituados como espaços compostos por elementos essenciais e que se retroalimentam ou, ainda, como uma rede de lugares que se conectam e estimulam a sociedade a se tornar sustentável e justa".

Para 96,25\% dos entrevistados durante as observações participantes $(\mathrm{n}=80)$, o bemestar animal foi uma preocupação constante nas visitas, $86,25 \%$ estão familiarizados com seu conceito aplicado em zoológicos, $10 \%$ não tem certeza, mas acreditam saber o significado de bem-estar animal e 3,75\% não possui conhecimentos. Esse termo está relacionado ao estado do animal em relação às tentativas de adaptar-se no ambiente (BROOM; MOLENTO, 2004). Esses autores indicam que "em qualquer avaliação de bem-estar, é necessário levar em conta as variações individuais ao enfrentar adversidades e nos efeitos que essas exercem sobre os animais" (BROOM; MOLENTO, 2004, p.1).

Atualmente, acredita-se que as práticas associadas ao bem-estar animal nos zoológicos devem estar intimamente relacionadas com seus PEA's, procurando melhorar o conhecimento dos visitantes e a imagem das instituições (PAGANI et al., 2015). Afinal, não há de fato razão que justifique a existência de um zoológico se este não proporcionar vivências educativas, simplesmente se limitando a mera exposição de animais para entretenimento (BRITO, 2012), pois o público deseja mais do que animais entediados (MORRIS, 1990).

Já sobre enriquecimento ambiental, 37,5\% são favoráveis às práticas desenvolvidas nos zoológicos, 6,25\% desfavoráveis e 56,25\% não tem certeza. Esses visitantes quando questionados sobre o tema, $68,75 \%$ assumiram não ter conhecimento, $17,5 \%$ sabem, mas não tinham certeza e apenas $13,75 \%$ afirmaram ter conhecimento sobre o conceito e as práticas de enriquecimento ambiental desenvolvida por zoológicos. Enriquecimentos ambientais são modificações no ambiente físico ou social do animal, combinando conhecimento prévio do habitat e comportamento natural, visando a redução dos níveis de estresse, melhoria na saúde e desempenho reprodutivo (BOERE, 2001; CELOTTI, 2001), aspectos sociais, cognitivos, físicos, sensoriais e alimentares (BLOOMSMITH; BRENT; SHAPIRO, 1991).

Durante a aplicação desse instrumento de pesquisa, foram constatadas práticas de enriquecimento ambiental ocorrendo no momento da intervenção. Entretanto, informalmente muitos visitantes argumentavam sobre a presença das estruturas humanizadas nos recintos (caixas de papelão embrulhadas) nas épocas de Natal, Páscoa e Halloween; bem como, sobre estruturas plásticas (garrafas PET) e folhas de diversos vegetais; que foram interpretadas como sujeira nos recintos, realçando a falta de conhecimento sobre conceito e práticas de enriquecimento ambiental realizada nos zoológicos.

A maioria dos frequentadores de zoológicos não reconhecem a importância do enriquecimento ambiental, tendo apenas uma vaga noção da técnica (PAGANI et al., 2015). Já para funcionários do Zoológico Municipal Parque Jacarandá (Uberaba, MG), manejar animais menos estressados seria mais fácil e ressaltando a importância dos processos de sensibilização na conscientização ambiental (SANTOS; SANTOS; AMORIM, 2015). As estratégias de enriquecimento ambiental despertam o interesse e estimulam os animais, tornando mais realista as observações dos visitantes (ALVARENGA et al., 2014).

As pesquisas em comportamento animal e práticas de enriquecimento ambiental tem procurado aproximar os recintos com ambientes de origem dos animais, reduzindo problemas de estresse em cativeiro (BRITO, 2012). Esses recintos se tornam mais interessantes e educativos, incentivando comportamentos naturais, contribuindo para melhorar o bem-estar físico e psicológico dos animais e aumentando as taxas reprodutivas, além de auxiliarem na conservação das espécies (CELOTTI, 2001).

Utilizando-se da ferramenta google alerts, os termos bem-estar animal, enriquecimento ambiental e zoológicos foram acompanhados na rede mundial de computadores, buscando entender como esses conceitos estão sendo divulgados pelos meios de comunicação e de que 
maneira eles estariam se relacionando às instituições zoológicas no Brasil ${ }^{16}$. Assim, ao longo de 1.011 dias de acompanhamento das notícias, foram obtidos 2.155 e-mails com 12.909 notícias relacionadas aos temas pesquisados (Tabela 11).

Tabela 11 - Análise dos e-mails e notícias acompanhadas, através da ferramenta google alerts, no período de 27 de outubro de 2016 a 04 de agosto de 2019

\begin{tabular}{lcccc}
\hline & Zoológico & Bem-estar animal & Enriquecimento Ambiental & Total \\
\hline E-mails & 999 & 960 & 196 & 2.155 \\
Notícias & 5.689 & 6.964 & 256 & 12.909 \\
\hline
\end{tabular}

Fonte: Elaboração dos autores

A categoria zoológico abordou diversos subtemas, como notícias de nascimento e morte de animais, propagandas e filmes, atividades desenvolvidas nas instituições, desastres, maustratos de visitantes com animais de zoológicos, doenças, roubo de animais, notícias sobre o acesso e horário de funcionamento de diferentes parques zoológicos; a avaliação de passeios e visitação dos internautas; readaptação, reintrodução e reprodução em cativeiro; bem como sobre aspectos de gestão pública e privada nos parques zoológicos, em voga devido às crises econômicas, em especial para os estados do Rio de Janeiro e do Rio Grande do Sul.

Em muitos casos, percebe-se que notícias que abordam os aspectos negativos são multiplicadas em maior número e por diversos canais de comunicação diferentes, como no caso de acidentes com animais em zoológicos ou morte de animais sob cuidados humanos. Muitas notícias relacionam-se ao nascimento de espécies, inclusive ameaçadas de extinção, em cativeiro, e sobre a morte de animais em zoológicos, independente dos motivos. Dentre as notícias foram encontradas algumas percepções contrárias à existência dos zoológicos, a destacar: "Zoológicos são instituições anacrônicas que, por natureza, violam os direitos dos animais. Causam danos a eles, deseducam a população e estão longe de se justificarem por razões científicas que beneficiem os próprios animais" (ZOOLÓGICO, 2016).

Essas notícias podem interferir diretamente na percepção da população sobre o funcionamento desses espaços, sejam eles públicos ou privados, cabendo às instituições o acompanhamento da divulgação midiática e o planejamento da divulgação de caráter científico, para que ocorra a contribuição para a alfabetização científica de seu público.

A categoria bem-estar animal envolveu notícias sobre a vaquejada, devido às discussões legais da atividade; sobre o sistema produtivo, exportação e regulamentação do comércio exterior; cuidado com animais de estimação, como gatos e cães, resgate de animais sob maustratos e a criação de ouvidorias e provedorias públicas, não trazendo muita correlação com as instituições zoológicas e as práticas por elas desenvolvidas. Quando ocorre o termo bem-estar animal associado ao termo zoológico ele também está relacionado às práticas de enriquecimento ambiental.

Já a categoria enriquecimento ambiental abordou a parte das práticas alimentares realizadas pelas instituições zoológicas, sendo que foram exclusivas para a oferta de presentes de natal aos animais, em diferentes zoológicos, e a disponibilização de picolés de frutas, carne e sangue. Outras práticas de enriquecimento ambiental não foram localizadas nas publicações. Nessa categoria, observou-se que as práticas divulgadas estão realmente relacionadas às datas festivas e ao enriquecimento ambiental alimentar, não conseguindo demonstrar a importância para o bem-estar animal quando desenvolvidas.

\footnotetext{
${ }^{16}$ Cabe ressaltar que não foram realizadas análises temporais e cruzadas das notícias com as percepções coletadas ao longo do período. Com o acompanhamento das notícias, buscou-se acompanhar a evolução dos aspectos positivos e negativos que podem permear as percepções acerca das instituições zoológicas no país. Sugere-se, assim, novos estudos que possibilitem avaliar, de maneira mais aprofundada, essas possíveis relações, questionando os visitantes sobre informações recebidas sobre a conservação da fauna em zoológicos.
} 
Esse tipo de monitoramento pode auxiliar o setor de comunicação e marketing dessas instituições, fazendo com que notícias importantes sobre as funções dos zoológicos sejam publicadas, atraindo um número maior de visitantes, esclarecendo seu funcionamento, e subsidiando programas informativos ao público, atrelados a Programas de Educação Ambiental já existentes ou em estruturação. Somente um acesso facilitado à grande quantidade de informações, seja a nível nacional ou internacional, permitirá um maior engajamento de todos, sociedade e administração, em uma solução viável para os problemas ambientais (DEL'OLMO, 2007).

\section{Considerações Finais}

Mesmo ocorrendo oscilações nas percepções dos visitantes sobre razões da existência, aspectos a ser considerados em um zoológico ideal, motivação das visitas ou meios de informação, foi detectado um padrão relacionado à idade e expectativas dos visitantes. Utilizar essas informações para subsidiar o planejamento de ações educativas ambientais é fundamental, pois alterar percepções equivocadas dos visitantes utilizando a estrutura biológica das instituições permitirá desenvolver aspectos básicos do pensamento científico, como observação, classificação, inferência, registros (MENEGAZZI, 2000).

O setor de comunicação e marketing dos zoológicos enfrenta grandes desafios para que a percepção dos visitantes e grupos contrários à sua existência seja ampliada, onde os esforços devem estar centrados nas atividades de conservação ex situ e apoiados pela sociedade civil. Assim, setores técnicos como biologia e educação devem trabalhar integrados, aprimorando práticas cotidianas nos zoológicos para que se tornem espaços educadores, embasando e auxiliando nas discussões sobre o desenvolvimento de políticas públicas atuais de Educação Ambiental e de Conservação de Fauna.

É fundamental que as práticas de Educação Ambiental realizadas nos zoológicos envolvam a comunidade de visitantes, despertando a compreensão sobre políticas públicas de Educação Ambiental e bem-estar animal. Acredita-se que a análise trazida sobre a percepção dos visitantes de quatro zoológicos localizados em Santa Catarina possa ser extrapolada para outras instituições de diversas regiões e estados brasileiros. Os esforços para a conservação faunística ex situ têm sido cada vez maiores, ao longo dos últimos anos, como demonstrado em diversos pontos da presente pesquisa. Basta que saibamos ampliar o entendimento sobre as funções dos zoológicos e as estruturas necessárias para que haja melhorias diárias e efetivas, que resultem na conservação da vida animal.

\section{Referências}

ACHUTTI, M. R. do N. G. O zoológico como ambiente educativo para vivenciar o ensino de ciências. 2003. 68f. Dissertação (Mestrado em Educação) - Universidade do Vale do Itajaí, Itajaí, 2003.

ACHUTTI, M. R. do N. G.; BRANCO, J. O. Abordagem ambiental na visita dos universitários ao zoológico do Parque Cyro Gevaerd em Balneário Camboriú, SC. In: SIMPÓSIO SUL BRASILEIRO DE EDUCAÇÃO AMBIENTAL, 2, 2003, Itajaí. Anais... Itajaí: UNIVALI, 2003. CD.

ALPZA. Cuestionario y Estándares de Acreditación de la Asociación latinoamericana de Parques Zoológicos y Acuarios: edición 2016-2017. 2017.

ALVARENGA, G. M.; SILVA, E. B. da; MENEZES, M. E. B. de; CARPI, L. C. F. G.; MARTINS, A. M. A. Enriquecimento ambiental em três recintos de Puma Concolor do criadouro conservacionista nex - no extinction. In: $39^{\circ}$ Congresso da Sociedade de Zoológicos e Aquários do Brasil, 2014, Bauru. $39^{\circ}$ Congresso da Sociedade de Zoológicos e Aquários do Brasil, 2014. 
AMARAL, G. B. do; SANTOS, R. M. O potencial educativo de praças como espaço educador sustentável. In: FÓRUM ONLINE EDUCAÇÃO, MEIO AMBIENTE E SUSTENTABILIDADE, 1, 2017. Tupã. Anais... 2017. Tupã: ANAP, 2017. p. 118-132. Disponível em:

<https://www.eventoanap.org.br/data/inscricoes/1965/form10817433.pdf>. Acesso em: 14 jun. 2021.

ANDERSON, M.J. A new method for non-parametric multivariate analysis of variance. Austral Ecology, Sidney, v. 26, n. 1, p. 32-46, feb. 2001. Disponível em: <https://doi.org/10.1111/j.14429993.2001.01070.pp.x>. Acesso em: 14 jun. 2021.

ARAGÃO, G. M. de O.; KAZAMA, R. Percepção ambiental de visitantes do Zoo de Brasília e a possibilidade de se aprender e ensinar nesse ambiente. Acta Scientiarum. Human and Social Sciences Maringá, v. 36, n. 1, p. 63-71, Jan./June, 2014.

AURICCHIO, A. L. Potencial da Educação Ambiental nos Zoológicos Brasileiros. Publicações avulsas do Inst. Pau Bras. Hist. Nat., São Paulo, n. 1. p.1-48, 1999.

BAZARRA, L. Los zoológicos en camino hacia la educación: manual para el educador. México DF: Secretaría de Educación Pública, 1994.

BLOOMSMITH, M. A.; BRENT, L.Y.; SHAPIRO, S. J. Guidelines for developing and managing na environmental program for nohuman-primates. Laboratory Animal Science, Mêmphis, v. 41, n. 4, p. 372-377, Aug. 1991.

BOERE, V. Behavior and environment enrichment. In: FOWLER, M. E.; CUBAS, Z. S. (Orgs.) Biology, medicine and surgery of South American wild animals. Ames: Iowa University Press, 2001. p. 263-266.

BRITO, A. G. de. O Jardim Zoológico enquanto espaço não formal para promoção do desenvolvimento de etapas do raciocínio científico. 2012. 114 f. Dissertação (Mestrado em Ensino de Ciências) - Universidade de Brasília, Brasília, 2012.

BROOM, D. M.; MOLENTO, C. F. M. Bem-Estar Animal: Conceito e questões relacionadas Revisão. Archives of Veterinary Science, Curitiba, v. 9, n. 2, p.1-11, 2004. Disponível em: <https://revistas.ufpr.br/veterinary/article/view/4057>. Acesso em: 14 jun. 2021.

CELOTTI, S. Guia para o enriquecimento das condições ambientais de cativeiro. London: Universities Federation for Animal Welfare, 2001.

CHRISTOFFERSEN, M. L.; BRANCO, J. O.; FURTADO, M. H. B. C. Regional zoos in Brazil and their specific role for environmental education. Herald Journal of Education and General Studies, v. 2, n. 3, p. 097-106, Aug. 2013.

CLARKE, K. R.; WARWICK, R. M. Change in marine communities: an approach to statistical analysis and interpretation. Natural Environmental Research Council, Plymouth, 1994. 176p.

DEL'OLMO, E. C. Informação ambiental como direito e dever fundamental. 2007, p. 18. Disponível em: http://www3.pucrs.br/pucrs/files/uni/poa/direito. Acesso em: 20 jan. 2017.

DEL RIO, V. Desenho urbano e revitalização na área portuária do Rio de Janeiro: a contribuição do estudo da percepção ambiental. 1991. 518p. Tese (Doutorado em Arquitetura e Urbanismo) Universidade de São Paulo, São Paulo, 1991. 
DEL RIO, V. Cidade da mente, cidade real: Percepção e revitalização da área portuária do RJ. In: DEL RIO, V.; OLIVEIRA, L. (Orgs.), Percepção ambiental: a experiência brasileira. São Carlos: Studio Nobel, 1996. 265p.

DIAS, J. C. C. Zoológicos e a Pesquisa Científica. Biológico, São Paulo, v. 65, n.1/2, p.127-128, Jan./Dez., 2003.

FERREIRA, C. P. Percepção Ambiental na Estação Ecológica de Juréia-Itatins. 2005. 114 f. Dissertação (Mestrado em Ciência Ambiental) - Universidade de São Paulo, São Paulo, 2005.

FONSECA, F. S. R. da; OLIVEIRA, L. G. Concepções de meio ambiente dos educadores ambientais do Zoológico de Goiânia: implicações nas atividades e contribuições para a formação do sujeito ecológico? Educar em Revista, Curitiba, n. 41, p. 231-246, Jul./Set. 2011.

FURTADO, M. H. B. C.; BRANCO, J. O. A percepção dos visitantes dos zoológicos de Santa Catarina sobre a temática ambiental. In: SIMPÓSIO SUL BRASILEIRO DE EDUCAÇÃO AMBIENTAL, 2, 2003, Itajaí. Anais... Itajaí: UNIVALI, CD.

FURTADO, M. H. B. C. Os zoológicos de Santa |Catarina e a percepção de seus visitantes sobre a temática ambiental. 2002. 87f. Dissertação (Mestrado Acadêmico em Educação) - Universidade do Vale do Itajaí, Itajaí, 2002.

FURTADO, A. S. P.; PINTO, C. R.; MAILAN, M. A. da S.; BORBA, R.; GOMES, P. G. S. C. M. Zoológico Bosque Guarani de Foz do Iguaçu-PR: um espaço para lazer ou aprendizagem? In: 13 Encontro Paranaense de Educação Ambiental, 2011, Ponta Grossa. $13^{\circ}$ Encontro Paranaense de Educação Ambiental, 2011.

GARCIA, V. A. R.; MARANDINO, M. Zoológicos: que mensagem estamos passando? Disponível em https://edisciplinas.usp.br/pluginfile.php/151125/mod_folder/content/0/Resenha\%202.2.\%20Garcia\%2 0e\%20Marandino_Zool\%C3\%B3gicos-Que\%20mensagem\%20estamos\%20passando.pdf >. Acesso em: 14 jun. 2021.

JACOBUCCI, D. F. C. Contribuições dos espaços não formais de educação para a formação da cultura científica. Em Extensão, Uberlândia, v. 7, n. 1, p. 55-66, 2008.

LOPES, L.; BOSA, C. R.; SILVA, J. D. da. Percepção ambiental dos visitantes do zoológico municipal de Curitiba-PR. Monografias ambientais, Santa Maria, v. 4, n. 4, p. 866-876, 2011.

LUTTERBACH, Angela A.; MENEGAZZI, Cristiane S. Mini curso de educação ambiental para educadores. In: XXII Congresso da Sociedade de Zoológicos do Brasil, 1998, Bahia... Anais... Bahia, 1998, p.151.

MENDES, P. C. Percepção Ambiental no Zoológico de Pomerode. Trabalho de conclusão de curso (Curso de Zootecnia). Universidade Federal de Santa Catarina, Florianópolis, 2014.

MENEGAZZI, C. S. Espacios Extra Escolares de Educación, Revista da Sociedade de Amigos da Fundação Zôo-Botânica, Belo Horizonte, v. 1, n.1, p.12-13, 2000.

MENEGAZZI, C. S. O Professor e o Jardim Zoológico no Ensino de Ciências. 2003. 143p. Dissertação (Mestrado em Educação). Universidade Federal de Minas Gerais, Belo Horizonte.

MERGULHÃO, M. C. Zoológico: uma sala de aula viva. 1998. 143f. Dissertação (Mestrado em Educação). Universidade de São Paulo, São Paulo, 1998. 
MILITÃO, C. Zoo - Enquadramento e Caracterização: História do Zoo. 2008. Disponível em https://tac9f.files.wordpress.com/2008/11/ficha-de-trabalho-nc2ba-1_historia-do-zoo.pdf. Acesso em: 18 fev. 2017

MMA. Ministério do Meio Ambiente. Programa Nacional de Educação Ambiental-ProNEA. 3 ed. Brasília: Ministério do Meio Ambiente, 2005.

MORRIS, D. O Contrato animal. Rio de Janeiro: Record, 1990. 175p.

ZOOLÓGICO: OAB/RJ derruba liminar e salva 1.300 vidas. Olhar Animal, 2016. Disponível em: $<$ https://olharanimal.org/zoologico-oabrj-derruba-liminar-e-salva-1-300-vidas/ > . Acesso em: 15 jun 2021.

PAGANI, R.S.; ARDANAZ, R.F..; MAAS, C.H.; CARNEIRO, L.A.; IZIDORO, T.D.; MACIEL, P.; NIGRO, N. P. Percepção dos visitantes do Zoo Pomerode quanto ao bem-estar animal e o enriquecimento ambiental. In: $39^{\circ}$ Congresso da Sociedade de Zoológicos e Aquários do Brasil, 2015, Foz do Iguaçu. $39^{\circ}$ Congresso da Sociedade de Zoológicos e Aquários do Brasil, 2015.

PROHNII, S. da S; COSTA, J. K.; ABREU, T. C. de; FONTANA, J. C.; SILVÉRIO, R. A.; FISCHER, M. L. Bioética ambiental: refletindo a questão ética envolvida na manutenção de animais cativos em zoológicos. 2015. Disponível em https://docplayer.com.br/7323393-Bioetica-ambientalrefletindo-a-questao-etica-envolvida-na-manutencao-de-animais-cativos-em-zoologicos.html. Acesso em: 23 jun. 2021.

SAAD, C. E. P., SAAD, F. M. D. O. B.; FRANÇA, J. Bem-estar em animais de zoológicos. Revista Brasileira Biociências, Porto Alegre, v. 40, p. 38-43, 2011.

SANTOS, C. M. dos; SANTOS, S. M. dos; AMORIM, H. P. C. Avaliação da percepção ambiental dos funcionários do Zoológico Municipal Parque Jacarandá (Uberaba-MG). In: $39^{\circ}$ Congresso da Sociedade de Zoológicos e Aquários do Brasil, 2015, Foz do Iguaçu. $39^{\circ}$ Congresso da Sociedade de Zoológicos e Aquários do Brasil, 2015.

SILVA, A. T.; MACEDO, M. E. A importância do Enriquecimento Ambiental para o bem-estar dos animais em zoológicos. Acervo da Iniciação científica, Belo Horizonte, n. 2, 2013. Disponível em: <https://www.metodista.br/revistas/revistas-izabela/index.php/aic/article/view/501> Acesso em: 17 jun. 2021.

SILVA, F.B. da; CECCON, S.; GÜNTZEL-RISSATO, C.; SILVEIRA, T.R. da; TEDESCO, C.D.; GRANDO, J.V. Educação Ambiental: interação no campus universitário através de trilha ecológica. REMEA-Revista Eletrônica do Mestrado em Educação Ambiental, v. 17, jul/dez., 2006.

SOUZA, R. S. de; ALBUQUERQUE, L. Sobre o olhar antropocêntrico: o ser humano e o jardim zoológico. INTERthesis, Florianópolis, v.12, n.1, p.117-129, Jan./Jun.2015.

TOMAZELLO, M. G. C.; FERREIRA, T. R. das C. Educação Ambiental: que critérios adotar para avaliar a adequação pedagógica de seus projetos? Ciência \& Educação, Bauru, v.7, n.2, p. 199-207, 2001.

WAZA - World Association of Zoos and Aquaria. Cuidando da vida selvagem: a estratégia mundial de bem-estar animal dos zoológicos e aquários. Gland: WAZA Executive Office, 2015. 


\section{Anexo 01 - Instrumento de coleta de dados primários: entrevistas estruturadas (questionários) aplicadas aos visitantes de parques zoológicos}

Parque zoológico:

Data da coleta:

\section{IDENTIFICAÇÃO}

Cidade de origem:

Idade:

Estado Civil: ( ) Solteiro ( ) Casado ( ) Separado ( ) União Estável ( ) Amasiado/Amigado ( ) Viúvo

1) Como chegou ao Zoológico?

( ) veículo particular ( ) ônibus de linha （ ) excursão （ ) outros

2) Veio acompanhado por:

( ) família ( ) amigos ( ) escola ( ) sozinho ( ) outros

3) Qual a frequência de suas visitas?

( ) primeira vez ( ) semanal ( ) mensal ( ) anual ( ) outros

4) Você considera o valor da entrada:

( ) bom/atraente/acessível ( ) caro/alto ( ) poderia ser mais (não se incomodaria em pagar)

\section{ASPECTOS AMBIENTAIS - PERCEPÇÃO AMBIENTAL}

1) Qual o motivo de sua visita ao zoológico? Apenas uma alternativa

( ) passar um dia de lazer em contato com a natureza

( ) observar os animais

( ) trazer os filhos

( ) outros

2) Qual a razão da existência dos zoológicos? Apenas uma alternativa

( ) conservação de espécies ameaçadas

( ) local de lazer para os visitantes

( ) educação ambiental

( ) refúgio de animais que não podem voltar para a natureza

( ) reprodução de espécies

( ) outros

3) Em sua opinião, como seria um zoológico ideal? Apenas uma alternativa

( ) com muitos animais de outros países

( ) onde os animais estejam bem adaptados

( ) com muitos animais brasileiros ameaçados de extinção

( ) onde existam programas de educação ambiental

( ) onde o público possa ver os animais com facilidade e bem de perto

( ) outros

4) Os zoológicos podem desenvolver educação ambiental como complemento do ensino (escola/universidade)? Apenas uma alternativa
( ) $\operatorname{sim}$
( ) não
( ) não tenho certeza

5) Você conhece ou já participou de atividades educativas ambientais aqui no zoológico? Apenas uma alternativa
( ) $\operatorname{sim}-($ ) conhece mas não participou
( ) já participou (Qual?:
( ) não ( ) não tenho certeza

6) Qual desses motivos você acredita ser o mais importante para levar um animal à extinção? Apenas uma alternativa
( ) destruição do local onde vive o animal
( ) poluição ambiental
( ) caça predatória
( ) comércio ilegal 
( ) outros

7) Qual desses meios você acredita que informa melhor sobre assuntos ligados ao meio ambiente? Apenas uma alternativa
( ) TV
( ) TV por assinatura
( ) Internet
( ) Revistas/Jornais
( ) Ensino Formal
( ) Zoológicos
( ) outros

8) Você sabe o que é bem-estar animal?
( ) não
( ) não tenho certeza
( ) sim: O que é bem-estar para você?

8b) COMPLEMENTAR A ANTERIOR: Quando você visita um zoológico, o bem-estar dos animais é uma preocupação para você?
( ) não
( ) não tenho certeza
( ) $\operatorname{sim}$

9) Você sabe o que é enriquecimento ambiental?
( ) $\operatorname{sim}$
( ) não
( ) não tenho certeza
10) Você é favorável a prática do enriquecimento ambiental?
( ) $\operatorname{sim}$
( ) não
( ) não tenho certeza
Porquê?

11) O que você achou dos recintos do zoológico?
( ) excelentes ( ) ótimos ( ) bons ( ) regulares
( ) péssimos
Complementação de resposta (em especial se for negativa):

12) Analisando os contextos atuais e suas experiências, você se coloca favorável à permanência da existência dos zoológicos?

( ) $\operatorname{sim}($ ) não ( ) não tem certeza

\section{OBSERVAÇÕES:}

